\title{
Avaliação dos impactos ambientais na área de influência direta do córrego da Estiva, município de Betim, MG, Brasil
}

Evaluation of environmental impacts in the area of influence direct of Estiva stream, Betim city, MG, Brazil

\author{
Thiago Santiago Soares, Mariana Aparecida Soares Côrtes, Angelina Dornelas Freitas e Fernanda Carla \\ Wasner Vasconcelos
}

santiago-2292@hotmail.com; mari.mcortes@gmail.com; angeldornellas@yahoo.com.br; fernanda.wasner@prof.una.br

Centro Universitário UMA, Belo Horizonte, MG, Brasil

\begin{abstract}
Resumo
Planejar o uso e ocupação de uma microbacia hidrográfica é fundamental para a correta utilização dos recursos hídricos. O objetivo desse trabalho é avaliar os impactos ambientais no córrego da Estiva - Betim (MG, Brasil), entre Julho e Setembro de 2014. Foi realizada a aplicação do Protocolo de Avaliação Rápida da Diversidade de Habitats em Trechos de Bacias Hidrográficas. Essa técnica oferece condições para levantar os impactos ambientais sobre trechos de cursos d'água através da avaliação de alguns parâmetros por observação. Os 1,34Km estudados foram setorizados em cinco trechos e para os dados obtidos com o Protocolo de Callisto, aplicou-se o teste Kruskall-Wallis. O resultado da somatória das notas atribuídas individualmente aos parâmetros foi de 12 em dias chuvosos, e 10 em dias secos, refletindo assim o nível de preservação do córrego, considerando-o impactado. Verificou-se diferença significativa para a mediana e os testes de condição do tempo, sendo observados diferentes impactos, tais como: ausência de mata ciliar, processos erosivos, presença de animais vetores de doenças, queimadas e descartes irregulares de resíduos sólidos (resíduos de construção civil, domiciliares e de poda de árvores) e efluentes líquidos (esgoto domiciliar) nos 1,34Km do Córrego do Estiva.
\end{abstract}

Palavras Chave: Caracterização. Qualidade Ambiental. Protocolo.

\begin{abstract}
Plan for the use and occupation of a watershed is essential to the proper use of water resources. The aim of this study is to evaluate the environmental impacts on stream Stowage - Betim (MG. Brazil), between July and September 2014 the implementation of the Rapid Assessment Protocol of Habitat Diversity in Excerpts from Watershed was performed. This technique offers conditions to raise the environmental impact on stretches of waterways by evaluating some parameters by observation. The 1,34Km studied were sectored into five sections and the data obtained with the Callisto Protocol, applied the Kruskal-Wallis test. The result of the sum of scores assigned to individual parameters was 12 on rainy days, and 10 dry days, reflecting the level of preservation of the stream, considering it impacted. There was a significant difference in the median and weather condition testing, observed different impacts, such as: absence of riparian vegetation, erosion, presence of animal disease vectors, fires and illegal discharges of solid waste (building waste civil, home and tree pruning) and wastewater (household sewage) in 1,34Km the stowage Stream.
\end{abstract}

Keywords: Characterization. Quality Environmental. Protocol. 


\section{Introdução}

É recente a percepção de que os recursos naturais não são inesgotáveis e que o desenvolvimento econômico deve harmonizar-se com o meio ambiente. Estes recursos estão cada vez mais escassos e vulneráveis em virtude de diversas atividades antrópicas (BITTENCOURT et al., 2012).

O desenvolvimento econômico, o crescimento populacional e a urbanização vêm sendo acompanhados por alterações no estilo de vida e nos modos de produção e consumo da população (GOUVEIA, 2012). Grandes centros urbanos enfrentam problemas relacionados ao saneamento básico: resíduos sólidos (acúmulo e destino), poluição e contaminação das águas, impermeabilização do solo, enchentes, alagamentos, deslizamentos, entre outros impactos que propiciam a segregação sócio espacial das camadas menos favorecidas da população. Tais impactos devem ser sanados e/ou compensados a partir de medidas mitigadoras e compensatórias, sendo necessária a avaliação de cada impacto para determinar a medida adequada a ser escolhida (SILVA, 2012).

A Avaliação de Impacto Ambiental (AIA) é um importante instrumento de política e gestão ambiental, vinculado ao processo de licenciamento ambiental em sua fase inicial. Esse instrumento foi introduzido no Brasil, em 1981, através da Política Nacional do Meio Ambiente (Política Nacional do Meio Ambiente, Lei $\mathrm{n}^{\mathrm{o}}$ 6.938 de 1981) e, desde 1986, é exigida para empreendimentos causadores de significativa degradação ambiental ou em áreas vulneráveis de acordo com a Resolução CONAMA 001/86 e a lei estadual de Minas Gerais no 7.772 , de 8 de setembro de 1980 que dispõe sobre a proteção, conservação e melhoria do meio ambiente. A AIA é uma ferramenta de caráter prévio, antecipatório e preventivo que equaciona o conflito entre a necessidade de apropriação e utilização dos recursos naturais e a manutenção do padrão aceitável da qualidade ambiental, por meio do estabelecimento de procedimentos e atividades sequenciadas (MARINHO et al., 2012).

Cabe ressaltar a necessidade de controlar o uso do solo e estabelecer critérios racionais de ocupação de uma região (ROCHA, 2012). É urgente a necessidade da conscientização da população nos hábitos quanto à ocupação desordenada sem planejamento, separação e destino dos resíduos sólidos, como forma de uma sociedade mais sustentável, a partir de um planejamento territorial mais rigoroso, sobretudo nas áreas urbanas habitadas mais carentes, que vem acumulando ao longo dos anos, danos aos materiais, à saúde coletiva podendo ocasionar desconfortos psicológicos e mortes na população (SILVA, 2012).

A importância deste estudo, assim como a dos demais estudos de impacto ambiental, é o de promover a garantia de proteção do direito fundamental ao meio ambiente ecologicamente equilibrado. A partir da avaliação e do conhecimento dos impactos ambientais sofridos pelo córrego da Estiva e sua qualidade ambiental é possível determinarmos medidas adequadas para a proteção do mesmo e mitigar os problemas visualizados que afetam a população residente em seu entorno, que sofre constantemente com enchentes, melhorando a qualidade de vida na região.

Este estudo tem como objetivo avaliar os impactos ambientais e a qualidade ambiental do córrego da Estiva, no município de Betim, Minas Gerais, identificando os impactos na Área de Influência Direta e propor medidas mitigadoras para os problemas identificados.

\section{Fundamentação Teórica}

O impacto ambiental ocorre, quando uma ação ou atividade produz alguma alteração com consequência favorável ou desfavorável no meio ou em alguns componentes do meio ambiente, tais como: os recursos hídricos e o solo (LOPES et al., 2011). O uso racional desses recursos, os quais perpassam pela não preservação e manejo sustentável, tem propiciado sua poluição e sua contaminação, provocando destruição da biota e afetando o próprio homem, visto a amplitude do processo que atinge diferentes localidades (PAZ \& PAIVA, 2011).

A Avaliação de Impacto Ambiental (AIA) é um instrumento de política pública que tem por objetivo subsidiar o planejamento e a tomada de decisão quanto à implantação de atividades com potencial poluidor, buscando alternativas adequadas e orientando a gestão socioambiental. É uma ferramenta de caráter prévio, 
antecipatório e preventivo que visa ao equacionamento do conflito entre a necessidade de apropriação e utilização dos recursos naturais e a manutenção do padrão aceitável da qualidade ambiental, por meio do estabelecimento de procedimentos e atividades sequenciadas (MARINHO et al., 2012). Apresenta como objetivos: $i$ ) assegurar que o ambiente é explicitamente considerado e incorporado no processo de decisão sobre propostas de desenvolvimento; ii) antecipar e evitar, minimizar ou compensar os efeitos adversos significativos sejam biofísicos sejam sociais; iii) proteger a produtividade e a capacidade dos sistemas naturais e dos processos ecológicos que mantêm as funções desses sistemas; iv) promover um desenvolvimento que seja sustentável e que otimize o uso dos recursos e as oportunidades de gestão (DIAS, 2013). Neste contexto, é um instrumento da política ambiental (introduzido no ordenamento jurídico brasileiro pela legislação vigente), sendo adotado em inúmeras jurisdições, por organizações internacionais e entidades privadas, para a atuação administrativa na defesa do meio ambiente (SILVA et al., 2012).

Para atingir seus propósitos, a AIA se desenvolve nas seguintes etapas: i) o procedimento de avaliação inicial para identificar se um projeto pode resultar, em sua implementação, em impactos ambientais (e também sociais) significativos e, assim, merecer ser objeto de avaliação de impacto ambiental; ii) o processo que busca identificar aspectos econômicos, sociais e ambientais significativos do projeto e eliminar aqueles insignificantes para a elaboração de uma AIA.

Os trabalhos que analisam os aspectos ambientais têm caráter funcional e fornecem bases para conservação dos recursos hídricos, da paisagem, da estabilidade geológica, da biodiversidade, do fluxo gênico da fauna e flora, proteção do solo e bem-estar das populações humanas (GARCIA, 2010). A delimitação das áreas de influência de um determinado projeto é um dos requisitos legais para avaliação de impactos ambientais, constituindo-se em fator de importância para o direcionamento da coleta de dados que subsidiarão o diagnóstico ambiental.

As áreas de influência são aquelas afetadas direta ou indiretamente pelos impactos, positivos ou negativos. Estas áreas normalmente assumem tamanhos diferenciados, dependendo da variável considerada (meio físico, biótico ou socioeconômico) (BRASIL, 1986). Classicamente, são utilizados os conceitos de: Área de Influência Direta (AID), como sendo aquele território em que as relações sociais, econômicas, culturais e os aspectos físicos e biológicos sofrem os impactos de maneira primária, tendo suas características alteradas, ou seja, há uma relação direta de causa e efeito; e Área de Influência Indireta (AII), em que os impactos ocorrem de maneira secundária ou indireta e, de modo geral, com menor intensidade, em relação ao anterior (CEPEMAR, 2004).

No ambiente urbano, muitos impactos ambientais estão relacionados com a ocupação desordenada e o crescimento de moradias em locais inapropriados como áreas de preservação, tais como: encostas, margens de rios, mananciais e até regiões de mangue (MUCELIN \& BELLINI, 2008). As áreas de preservação foram definidas pelo Código Florestal, posteriormente, de acordo com a Lei $\mathrm{n}^{\mathrm{o}}$ 6.938/81, estas áreas foram consideradas como reservas ecológicas, criadas para proteger o ambiente natural, o que significa que não são áreas apropriadas para alteração de uso da terra, devendo estar cobertas com a vegetação original. O Sistema Nacional de Unidades de Conservação (SNUC) é o conjunto de Unidades de Conservação (UC) federais, estaduais e municipais. É composto por 12 categorias de UC, cujos objetivos específicos se diferenciam quanto à forma de proteção e usos permitidos: aquelas que precisam de maiores cuidados, pela sua fragilidade e particularidades, e aquelas que podem ser utilizadas de forma sustentável e conservadas ao mesmo tempo. O SNUC foi instituído pela Lei $\mathrm{n}^{-}$9.985, de 18 de Julho de 2000 de forma a potencializar o papel das UC, de modo que sejam planejadas e administradas de forma integrada com as demais UC, assegurando que amostras significativas e ecologicamente viáveis das diferentes populações, habitats e ecossistemas estejam adequadamente representados no território nacional e nas águas jurisdicionais. Para isso, o SNUC é gerido pelas três esferas de governo (federal, estadual e municipal) (Sistema Nacional de Unidades de Conservação da Natureza, Lei no 9.985, de 18 de Julho de 2000). A cobertura vegetal nestas áreas irá atenuar os efeitos erosivos e a lixiviação dos solos, contribuindo 
também para regularização do fluxo hídrico, redução do assoreamento dos cursos d'água e reservatórios, e trazendo benefícios para a fauna e flora. Com a finalidade de adequar as leis federais, adaptando-as às peculiaridades regionais, o Decreto $\mathrm{n}^{\mathrm{o}}$ 33.944/92, que regulamenta a Lei $\mathrm{n}^{\mathrm{o}}$ 10.561/91, em seu art. $7^{\mathbf{0}}$ estabelece os critérios para delimitação de áreas de preservação permanente. A adoção desses em levantamentos para demarcação dessas áreas, realizados por órgãos ambientais pertinentes, encontra limitações operacionais e culturais, o que contribui para o uso inadequado dos solos nesses locais (COSTA et al., 1996).

As atividades humanas expandidas pelo crescimento populacional vêm gerando impactos de forma cada vez mais rápida e ampla que acarretam em perdas da diversidade biológica e de ecossistemas (SILVA \& LATINI, 2014). Para alcançar certa harmonia entre as atividades econômicas e a preservação ambiental, os estudos de impactos ambientais em áreas urbanas são necessários para o planejamento e um manejo adequado destas áreas.

Com a expansão das cidades, há um aumento da pressão antrópica sobre os corpos hídricos presentes nas mesmas (ARAÚJO \& BARBOSA, 2010). Dentro desse contexto ainda se encontram os conflitos na utilização dos recursos hídricos pelas indústrias, agricultura, pecuária, abastecimento público que necessitam da água para sua manutenção. Através das políticas públicas ambientais, é possível o planejamento e desenvolvimento de projetos focados na gestão dos recursos hídricos (BARBAROTO et al., 2013).

O Protocolo de Callisto et al. (2002) pode ser considerado então como uma importante ferramenta para a Avaliação de Impactos Ambientais, pois permite avaliar os níveis de impactos em trechos de rios e/ou córregos utilizando-se de uma metodologia de fácil e rápida aplicação. No estudo em questão, o protocolo permitiu a avaliação da qualidade ambiental do trecho estudado do córrego da Estiva mostrando-se uma importante ferramenta simples e eficaz para se utilizar em atividades de campo, demonstrou também, ser um ótimo recurso educativo para a análise de questões pertinentes à avaliação de impacto ambiental de bacias hidrográficas. De acordo com Callisto et al. (2002), o protocolo pode ser útil em atividades de ensino de graduação e pós-graduação, na formação de profissionais nas áreas de ecologia e ciências ambientais, mesmo com pouco treinamento na área de estudo.

\section{Métodos de Pesquisa}

Nesta seção será apresentada a metodologia utilizada para a realização do trabalho, sendo dividida em Área de estudo, contendo brevemente uma caracterização da área em que se localiza o objeto de estudo e os Procedimentos Metodológicos, abrangendo toda a metodologia utilizada no registro, identificação e coleta de dados.

\section{1 Área de Estudo}

Betim é um município brasileiro da Região Metropolitana de Belo Horizonte, estado de Minas Gerais, fundado em 17 de dezembro de 1938. A região fazia parte de uma importante rota de bandeirantes que vinham de São Paulo a Pitangui. Assim, como várias cidades surgiram nas trilhas das tropas e nas rotas dos bandeirantes, Betim, antes de assim se chamar, fazia parte desse entrecruzar de caminhos, sendo passagem e pousada de tropeiros (BETIM, 2014).

O córrego da Estiva está situado no município de Betim (MG), na regional Alterosas, entre os bairros Cruzeiro do Sul e Jardim Alterosa, abrangendo tanto a zona urbana quanto a zona rural. Sua nascente está localizada em uma zona de interesse ambiental, desaguando no Rio Betim em uma área urbana. Geograficamente, sua nascente está situada a uma latitude $19^{\circ} 55^{\prime} 17.72^{\prime \prime}$ sul e longitude $44^{\circ}$ $08^{\prime} 47.55^{\prime \prime}$ oeste, e sua foz a $19^{\circ} 56^{\prime} 12.05^{\prime \prime}$ sul e $44^{\circ} 10^{\prime} 35.19^{\prime \prime}$ oeste.

De acordo com o Plano Diretor de Betim (2011), para o uso e ocupação dos solos, a regional Alterosas é dividida nas seguintes zonas: Zona Residencial Mista em Área de Interesse Ambiental, Zona Residencial Rural, Residencial Mista-Centros e Zona de Represa (Barragem Várzea das Flores) (BETIM, 2011).

O córrego da Estiva (Figura 1) é um curso d'água que não apresenta trechos rápidos e/ou corredeiras. Em períodos secos, o fluxo do córrego é pequeno e a lâmina de água praticamente escassa. Suas margens são muito instáveis, existindo áreas descobertas e muito erodidas, são ainda ocupadas por moradias 
irregulares, como casas, chácaras, comércio e até mesmo fábricas. As margens do córrego são desprovidas de mata ciliar e a cobertura vegetal do leito é composta basicamente por gramíneas.

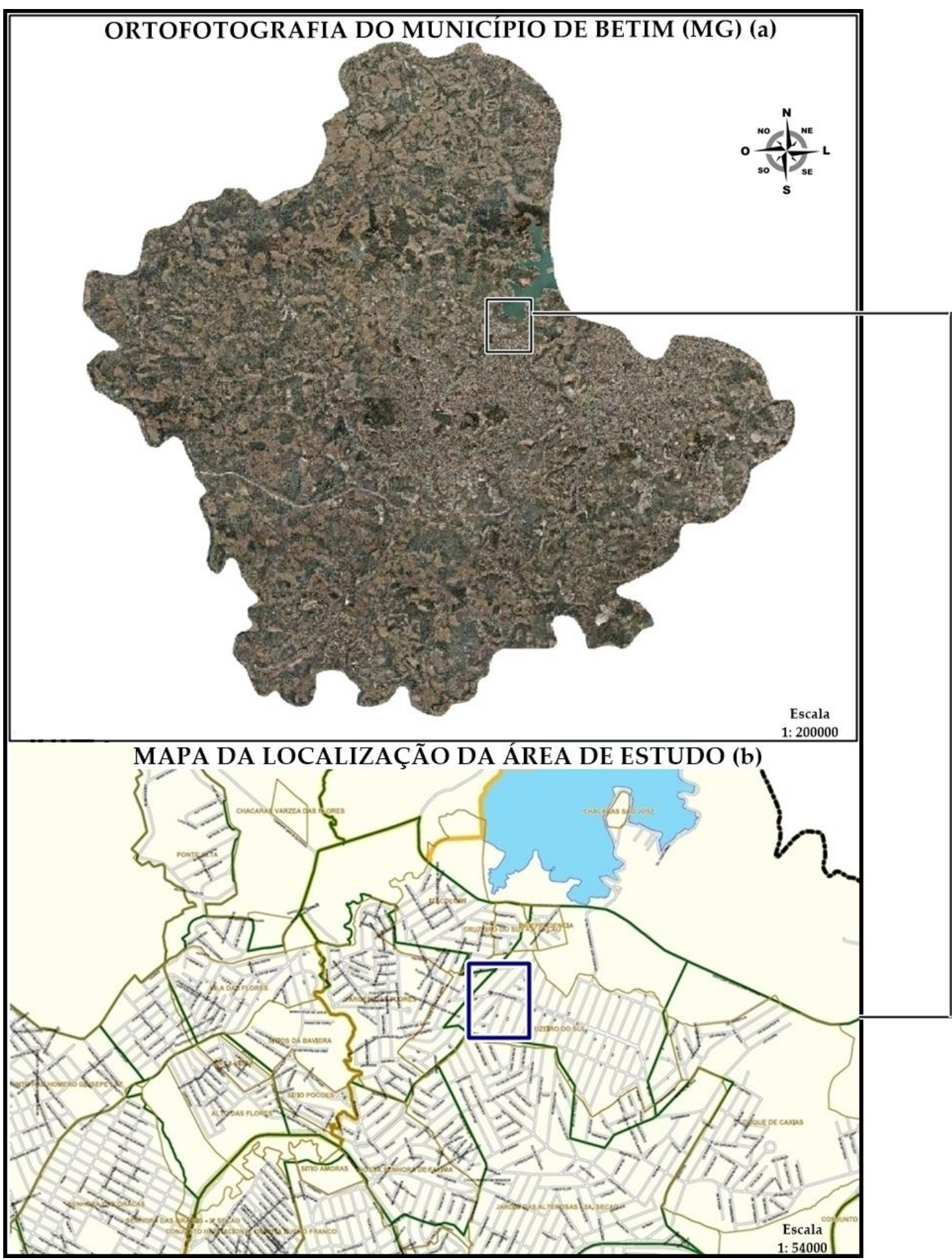

Figura 1: Ortofotografia do Município de Betim (a) e Mapa de Localização da Área de Estudo (b) (No quadro em azul, localização do córrego do Estiva).

Fonte: Instituto de Pesquisa e Política Urbana de Betim - IPPU e Prefeitura Municipal de Betim. 


\subsection{Procedimentos Metodológicos}

A metodologia aplicada contemplou o reconhecimento do local de estudo e visitas in loco.

A delimitação da AID (Figura 2) baseouse na possibilidade de registrar impactos significativos e em premissas como: Áreas com melhor infraestrutura sugere-se uma melhor coleta de resíduos, um melhor sistema de saneamento, um menor aparecimento de animais vetores, uma incidência menor de inundações, menor ocupação irregular das margens e, córregos preservados possuem maior presença de mata ciliar.

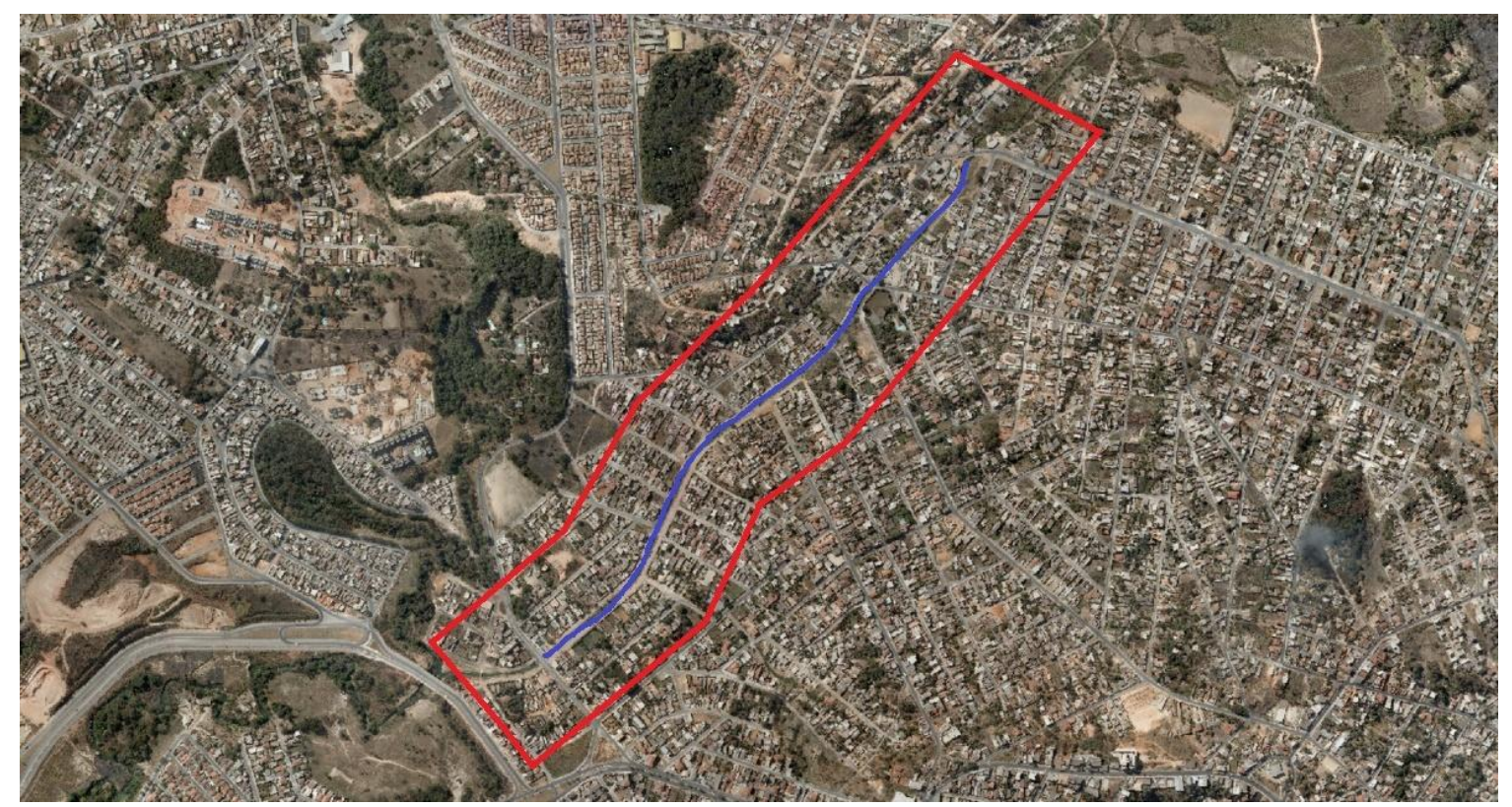

Figura 2: Delimitação da Área de Influência Direta (vermelho) do trecho estudado do córrego da Estiva (azul). Fonte: Instituto de Pesquisa e Política Urbana de Betim - IPPUB.

Para a delimitação da AID no mapa, utilizou-se uma ortofotografia da área estudada através do Instituto de Pesquisa e Política Urbana de Betim - IPPUB e a ferramenta 'Adicionar Caminho'. Definiu-se então como AID, 150 metros a partir de cada margem do córrego no perímetro de $1,34 \mathrm{Km}$ situado na área urbana, visto que o córrego tem aproximadamente $5 \mathrm{Km}$ de extensão.

A avaliação, registro e coleta de dados foram realizados, mediante registros fotográficos e os pontos de coleta identificados com aparelho GPS (Etrex H Garmim).

Foram realizadas 10 visitas de campo ao córrego da Estiva no período de Julho a Setembro, no ano de 2014, para avaliar as características do córrego (grau de impactos, condições do ambiente, bem como o nível de conservação das condições naturais), conforme Araújo \& Barbosa (2010) e identificar os impactos ambientais.

Nos pontos de coleta identificados, a avaliação da qualidade ambiental do córrego investigado e de sua AID foi realizada com a aplicação do Protocolo de Avaliação Rápida da Diversidade de Habitats em Trechos de Bacias Hidrográficas, proposto por Callisto et al. (2002), que consiste em um protocolo de percepção visual. Foram avaliados 60 pontos (28 em dias secos e 32 em dias chuvosos) localizados no trecho estabelecido. Essa técnica oferece condições para identificar os impactos ambientais das atividades antrópicas sobre trechos de cursos d'água, através da avaliação da ocupação das margens, extensão de mata ciliar, efluentes domésticos e resíduos sólidos descartados incorretamente.

Este Protocolo constitui uma importante ferramenta em programas de monitoramento de qualidade ambiental em ambientes aquáticos (CALLISTO et al., 2002). De acordo com o referido Protocolo, o resultado final da somatória das notas atribuídas individualmente aos parâmetros listados, reflete o nível de preservação das condições ecológicas dos trechos das bacias hidrográficas estudados. A faixa de 0 
a 40 pontos representa trechos impactados; de 41 a 60 pontos representa trechos alterados e acima de 61, os trechos são considerados naturais.

Adaptações foram realizadas no Protocolo de Callisto et al. (2002) pelos autores do presente trabalho para que o mesmo se adequasse melhor aos objetivos propostos. Alguns parâmetros foram retirados, pois não eram compatíveis à área de estudo escolhida, então, ao invés de 22 parâmetros como proposto por Callisto, apenas 14 foram avaliados (Quadro 1). De acordo com as modificações, a interpretação para a somatória das notas atribuídas aos parâmetros é: A faixa de 0 a 24 pontos representa trechos impactados; de 25 a 36 pontos representa trechos alterados e, acima de 36, os trechos são considerados naturais. A alteração desses valores se fez necessária, pois a nota máxima atribuída aos 22 parâmetros avaliados por Callisto et al. (2002) totalizam 100 pontos, e a nota máxima atribuída aos 14 parâmetros avaliados no presente trabalho corresponde a 60 pontos.

A identificação e a caracterização qualitativa dos impactos ambientais foram realizadas a partir da utilização da técnica check list, uma listagem de impactos ambientais que contemplam o potencial transformador do ambiente físico, biótico e antrópico, de causas impactantes conhecidas (LOPES et al., 2011). Para cada um dos impactos que foram listados, foram propostas medidas mitigadoras.

O córrego da Estiva foi dividido em cinco trechos, cada um contendo 12 pontos, para aplicação dos testes estatísticos Kruskal-Wallis, em que foram avaliadas as diferenças entre as medianas para os cinco trechos. A partir desses testes, também foi avaliada a diferença entre os pontos marcados às margens esquerda e direita $\mathrm{e}$ para condição do tempo (dia chuvoso e dia seco).

Quadro 1: Protocolo de Avaliação Rápida da Diversidade de Habitats em Trechos de Bacias Hidrográficas, modificado do protocolo proposto por Callisto et al. (2002).

\begin{tabular}{|c|c|c|c|}
\hline \multicolumn{2}{|c|}{ Localização Geográfica: } & \multicolumn{2}{|l|}{ Data da Coleta: } \\
\hline \multicolumn{2}{|l|}{ Hora da Coleta: } & \multicolumn{2}{|c|}{ Tempo (Situação do dia): } \\
\hline \multicolumn{2}{|c|}{ Modo de Coleta (Coletor): } & \multicolumn{2}{|c|}{ Tipo de Ambiente: } \\
\hline \multirow{2}{*}{ PARÂMETROS } & \multicolumn{3}{|c|}{ PONTUAÇÃO } \\
\hline & 4 Pontos & 2 Pontos & 0 Pontos \\
\hline $\begin{array}{c}\text { 1. Tipo de ocupação } \\
\text { das margens do corpo } \\
\text { d'água (principal } \\
\text { atividade) }\end{array}$ & $\begin{array}{l}\text { Vegetação } \\
\text { Natural }\end{array}$ & $\begin{array}{l}\text { Campo de pastagem/ } \\
\text { Agricultura/ } \\
\text { Monocultura/ } \\
\text { Reflorestamento } \\
\end{array}$ & $\begin{array}{c}\text { Residencial/ } \\
\text { Comercial/Industrial }\end{array}$ \\
\hline 2.Alterações Antrópicas & Ausente & $\begin{array}{l}\text { Alterações de origem } \\
\text { doméstica (esgoto, lixo) }\end{array}$ & $\begin{array}{l}\text { Alterações de origem } \\
\text { industrial/urbana } \\
\text { (fábricas, siderurgias) }\end{array}$ \\
\hline $\begin{array}{l}\text { 3. Cobertura Vegetal do } \\
\text { Leito }\end{array}$ & Total & Parcial & Ausente \\
\hline 4. Odor do Córrego & Nenhum & Esgoto (Ovo Podre) & Óleo/Industrial \\
\hline $\begin{array}{c}\text { 5. Transparência da } \\
\text { Água }\end{array}$ & Transparente & Turva & Opaca ou colorida \\
\hline $\begin{array}{c}\text { 6. Erosão próxima ou } \\
\text { nas margens do córrego } \\
\text { e assoreamento em seu } \\
\text { leito }\end{array}$ & Ausente & Moderada & Acentuada \\
\hline $\begin{array}{l}\text { 7. Coleta de resíduos } \\
\text { no entorno do córrego. }\end{array}$ & Total & Parcial & Nenhum \\
\hline $\begin{array}{l}\text { 8. Aparição de Animais } \\
\text { Vetores }\end{array}$ & Nunca & Às vezes & Sempre \\
\hline
\end{tabular}

Fonte: CALLISTO et al., 2002. 
Quadro 2: Continuação do Protocolo de Avaliação Rápida da Diversidade de Habitats em Trechos de Bacias Hidrográficas, modificado do protocolo proposto por Callisto et al. (2002).

\begin{tabular}{|c|c|c|c|c|}
\hline \multirow{2}{*}{ PARÂMETROS } & \multicolumn{4}{|c|}{ PONTUAÇÃO } \\
\hline & 5 Pontos & 3 Pontos & 2 Pontos & 0 Pontos \\
\hline $\begin{array}{l}\text { 10. Presença de } \\
\text { rápidos }\end{array}$ & $\begin{array}{c}\text { Rápidos e } \\
\text { corredeiras } \\
\text { presentes e bem } \\
\text { desenvolvidas }\end{array}$ & $\begin{array}{c}\text { Rápidos e } \\
\text { corredeiras } \\
\text { presentes, mas } \\
\text { não } \\
\text { desenvolvidas }\end{array}$ & $\begin{array}{c}\text { Trechos rápidos } \\
\text { podem estar } \\
\text { ausentes }\end{array}$ & $\begin{array}{l}\text { Rápidos ou } \\
\text { corredeiras } \\
\text { inexistentes }\end{array}$ \\
\hline $\begin{array}{l}\text { 11. Característica } \\
\text { do fluxo da água }\end{array}$ & $\begin{array}{c}\text { Fluxo } \\
\text { relativamente igual } \\
\text { em toda a largura } \\
\text { do córrego; mínima } \\
\text { quantidade de } \\
\text { substrato exposta }\end{array}$ & $\begin{array}{l}\text { Lâmina d'água } \\
\text { acima de } 75 \% \text { do } \\
\text { canal do córrego; } \\
\text { ou menos de } 25 \% \\
\text { do substrato } \\
\text { exposto }\end{array}$ & $\begin{array}{l}\text { Lâmina d'água } \\
\text { entre } 25 \text { e } 75 \% \text { do } \\
\text { canal do córrego } \\
\text { e/ou maior parte } \\
\text { do substrato } \\
\text { exposto }\end{array}$ & $\begin{array}{l}\text { Lâmina } \\
\text { d'água } \\
\text { escassa }\end{array}$ \\
\hline $\begin{array}{l}\text { 12. Presença de } \\
\text { mata ciliar }\end{array}$ & $\begin{array}{l}\text { Acima dos } 90 \% \\
\text { com vegetação } \\
\text { ripária nativa, } \\
\text { incluindo árvores, } \\
\text { arbustos ou } \\
\text { macrófitas; mínima } \\
\text { evidência de } \\
\text { desflorestamento, } \\
\text { todas as plantas } \\
\text { atingindo o } \\
\text { tamanho normal }\end{array}$ & $\begin{array}{c}\text { Entre } 70 \text { e } 90 \% \\
\text { com vegetação } \\
\text { ripária nativa; } \\
\text { desflorestamento } \\
\text { evidente, mas não } \\
\text { afetando o } \\
\text { desenvolvimento } \\
\text { da vegetação; } \\
\text { maioria das } \\
\text { plantas atingindo } \\
\text { o tamanho } \\
\text { normal }\end{array}$ & $\begin{array}{l}\text { Entre } 50 \text { e } 70 \% \\
\text { com vegetação } \\
\text { ripária nativa; } \\
\text { desflorestamento } \\
\text { óbvio; trechos } \\
\text { com solo exposto } \\
\text { ou vegetação } \\
\text { eliminada; menos } \\
\text { da metade das } \\
\text { plantas atingindo } \\
\text { a altura normal }\end{array}$ & $\begin{array}{c}\text { Menos de } \\
50 \% \text { da mata } \\
\text { ciliar nativa; } \\
\text { desflorestam } \\
\text { ento muito } \\
\text { acentuado }\end{array}$ \\
\hline $\begin{array}{l}\text { 13. Extensão da } \\
\text { mata ciliar }\end{array}$ & $\begin{array}{c}\text { Largura da } \\
\text { vegetação ripária } \\
\text { maior que } 18 \mathrm{~m} ; \\
\text { sem influência de } \\
\text { atividades } \\
\text { antrópicas }\end{array}$ & $\begin{array}{c}\text { Largura da } \\
\text { vegetação ripária } \\
\text { entre } 12 \text { e } 18 \mathrm{~m} ; \\
\text { mínima influência } \\
\text { antrópica }\end{array}$ & $\begin{array}{c}\text { Largura da } \\
\text { vegetação ripária } \\
\text { entre } 6 \text { e } 12 \mathrm{~m} ; \\
\text { influência } \\
\text { antrópica intensa }\end{array}$ & $\begin{array}{c}\text { Largura da } \\
\text { vegetação } \\
\text { ripária menor } \\
\text { que } 6 \mathrm{~m} ; \\
\text { vegetação } \\
\text { restrita ou } \\
\text { ausente } \\
\text { devido à } \\
\text { atividade } \\
\text { antrópica } \\
\end{array}$ \\
\hline $\begin{array}{l}\text { 14. Estabilidade } \\
\text { das margens }\end{array}$ & $\begin{array}{c}\text { Margens estáveis; } \\
\text { evidência de erosão } \\
\text { mínima ou ausente; } \\
\text { pequeno potencial } \\
\text { para problemas } \\
\text { futuros. Menos de } \\
5 \% \text { da margem } \\
\text { afetada }\end{array}$ & $\begin{array}{c}\text { Moderadamente } \\
\text { estáveis; } \\
\text { pequenas áreas de } \\
\text { erosão frequentes; } \\
\text { entre } 5 \text { e } 30 \% \text { da } \\
\text { margem com } \\
\text { erosão }\end{array}$ & $\begin{array}{l}\text { Moderadamente } \\
\text { instável; entre } 30 \\
\text { e } 60 \% \text { da margem } \\
\text { com erosão. Risco } \\
\text { elevado de erosão } \\
\text { durante enchentes }\end{array}$ & $\begin{array}{c}\text { Instável; } \\
\text { muitas áreas } \\
\text { com erosão; } \\
\text { frequentes } \\
\text { áreas } \\
\text { descobertas } \\
\text { nas curvas do } \\
\text { córrego; } \\
\text { erosão óbvia } \\
\text { entre } 60 \text { e } \\
\text { 100\% da } \\
\text { margem }\end{array}$ \\
\hline
\end{tabular}




\section{Resultados e Discussão}

A partir das visitas realizadas ao córrego da Estiva (MG), os impactos ambientais mais significativos e que estão contribuindo para a deterioração da qualidade ambiental daquela área foram identificados, são eles: degradação e/ou remoção da mata ciliar, lançamento de esgoto doméstico, moradia irregular, disposição inadequada de resíduos sólidos, queimadas e presença de animais transmissores de doenças, corroborando com os estudos de Crispim et al. (2013). Um grave problema ambiental observado nos trechos do córrego, localizados nas planícies de inundação, é a retirada das matas ciliares. A retirada da vegetação das margens do córrego elimina as barreiras naturais expondo as margens à erosão (BAILLY et al., 2012) facilita o transporte de sedimentos (FRANÇA et al., 2013) e o assoreamento do leito do córrego (BELLUTA et al., 2014). Além disso, aumenta o fluxo da correnteza, reduz a capacidade de retenção e infiltração de água no solo, aumenta os efeitos das enchentes e inundações, e também podem ocorrer desequilíbrios climáticos e diminuição da biodiversidade da região (fauna e flora) (VANDERLEY \& SILVA, 2015).

A criação de animais ao longo do córrego, como equinos, bovinos e aves, causa mau odor em consequência das fezes; surgimento de microrganismos patogênicos e poluição biológica, física e química dessa água. Essa prática, associada ao entulho e resíduos sólidos urbanos às margens atrai ainda, muitos animais vetores de doenças e/ou peçonhentos, conforme observado nesse diagnóstico, ratos, baratas, cobras e escorpiões são constantes no trecho estudado.

O crescimento urbano desordenado e não planejado dos bairros Cruzeiro do Sul e Jardim Alterosa é outro problema observado na área de estudo. A construção de imóveis as margens do córrego causa impermeabilização do solo e, consequentemente, aumento na frequência de inundações. Outro problema constatado no córrego da Estiva é o lançamento de efluentes in natura diretamente no curso d'água. Essa conduta adotada pela população desses bairros resulta na degradação do meio ambiente (físico, biótico e antrópico), a qual pode ser exemplificada pela contaminação das águas pluviais devido ao transporte de poluentes, crescimento excessivo de algas, odores desagradáveis, prejuízo da qualidade estética e paisagística, depósito de lodo, perda ou redução dos habitats naturais (terrestres ou aquáticos); riscos ao abastecimento da população; aparição de vetores responsáveis pela transmissão de doenças; comprometimento da vida aquática; entre outros (CRISPIM et al., 2013).

Resíduos Sólidos Urbanos (RSUs), popularmente chamados de lixo urbano, são resultantes da atividade doméstica e comercial das povoações e, apresentam diversidade e complexidade (CHERUBINI, 2008; FERREIRA et al., 2014). A disposição inadequada dos RSUs é inadequada e foi observada na AID e AII do córrego. Esses resíduos podem causar poluição do solo, água e ar; poluição visual; proliferação de vetores, maus odores e comprometer a qualidade de vida e da saúde humana conforme estudos de Silva \& Silva (2015).

Durante as visitas in loco na área de estudo, observou-se que as margens do córrego que não foram ocupadas de fato, tornaram-se depósitos irregulares de resíduos da construção civil, de resíduos de poda das árvores, resíduos domiciliares ou, até mesmo, de resíduos eletrônicos, o que gera, de certa forma, um desconforto por parte da população devido à estética desagradável e o surgimento dos problemas que são resultantes dessa ação (CRISPIM et al., 2013) e que pela diversidade implicam em medidas mitigadoras diferenciadas.

Nesse trecho do córrego, várias áreas apresentaram focos e indícios de queimadas, utilizadas tanto para limpeza de lotes quanto para sanear os resíduos sólidos conforme Vieira et al. (2015).

De acordo com o resultado da aplicação do Protocolo de Avaliação Rápida da Diversidade de Habitats em Trechos de Bacias Hidrográficas, adaptado de Callisto et al. (2002), não houve diferenças significativas entre os resultados da pontuação para cada um dos pontos de coleta analisados, todos eles foram considerados impactados.

O resultado final da somatória das notas atribuídas individualmente aos parâmetros listados para cada um dos pontos foi de 12, em dias chuvosos (Tabela 1) e 10, em dias secos, com exceção de um, que recebeu nota 8 (Tabela 2), indicando que tanto em dia seco quanto chuvoso 
o córrego é considerado impactado. Os 1,34Km analisados do córrego apresentaram homogeneidade nos impactos, devido à urbanização nas AID e AII, que contribuem com os mesmos impactos em toda a sua extensão (lançamento de esgoto direto no córrego; descarte de resíduos sólidos e de construção civil nas margens, destruição da mata ciliar, queimadas, entre outros).

Tabela 1: Pontuação final para os pontos analisados através do Protocolo de Avaliação Rápida da Diversidade de Habitats em Trechos de Bacias Hidrográficas, em dia chuvoso.

\begin{tabular}{c|ccccccccccccccc}
\multicolumn{10}{c}{} & \multicolumn{10}{c}{ Pontuação Final: Pontos analisados em dia chuvoso } \\
\hline Parâmetro & $\mathbf{1}$ & $\mathbf{2}$ & $\mathbf{3}$ & $\mathbf{4}$ & $\mathbf{5}$ & $\mathbf{6}$ & $\mathbf{7}$ & $\mathbf{8}$ & $\mathbf{9}$ & $\mathbf{1 0}$ & $\mathbf{1 1}$ & $\mathbf{1 2}$ & $\mathbf{1 3}$ & $\mathbf{1 4}$ \\
\hline $\mathbf{1}$ & & & & & & & & & & & & & & \\
$\mathbf{2}$ & 0 & 0 & 0 & 0 & 0 & 0 & 0 & 0 & 0 & 0 & 0 & 0 & 0 & 0 \\
$\mathbf{3}$ & 2 & 2 & 2 & 2 & 2 & 2 & 2 & 2 & 2 & 2 & 2 & 2 & 2 & 2 \\
$\mathbf{4}$ & 2 & 2 & 2 & 2 & 2 & 2 & 2 & 2 & 2 & 2 & 2 & 2 & 2 & 2 \\
$\mathbf{5}$ & 4 & 4 & 4 & 4 & 4 & 4 & 4 & 4 & 4 & 4 & 4 & 4 & 4 & 4 \\
$\mathbf{6}$ & 2 & 2 & 2 & 2 & 2 & 2 & 2 & 2 & 2 & 2 & 2 & 2 & 2 & 2 \\
$\mathbf{7}$ & 0 & 0 & 0 & 0 & 0 & 0 & 0 & 0 & 0 & 0 & 0 & 0 & 0 & 0 \\
$\mathbf{8}$ & 0 & 0 & 0 & 0 & 0 & 0 & 0 & 0 & 0 & 0 & 0 & 0 & 0 & 0 \\
$\mathbf{9}$ & 0 & 0 & 0 & 0 & 0 & 0 & 0 & 0 & 0 & 0 & 0 & 0 & 0 & 0 \\
$\mathbf{1 0}$ & 0 & 0 & 0 & 0 & 0 & 0 & 0 & 0 & 0 & 0 & 0 & 0 & 0 & 0 \\
$\mathbf{1 1}$ & 0 & 0 & 0 & 0 & 0 & 0 & 0 & 0 & 0 & 0 & 0 & 0 & 0 & 0 \\
$\mathbf{1 2}$ & 2 & 2 & 2 & 2 & 2 & 2 & 2 & 2 & 2 & 2 & 2 & 2 & 2 & 2 \\
$\mathbf{1 3}$ & 0 & 0 & 0 & 0 & 0 & 0 & 0 & 0 & 0 & 0 & 0 & 0 & 0 & 0 \\
$\mathbf{1 4}$ & 0 & 0 & 0 & 0 & 0 & 0 & 0 & 0 & 0 & 0 & 0 & 0 & 0 & 0 \\
Pontuação Final & 0 & 0 & 0 & 0 & 0 & 0 & 0 & 0 & 0 & 0 & 0 & 0 & 0 & 0 \\
\hline Situação & 12 & 12 & 12 & 12 & 12 & 12 & 12 & 12 & 12 & 12 & 12 & 12 & 12 & 12 \\
\hline & $\mathrm{I}$ & $\mathrm{I}$ & $\mathrm{I}$ & $\mathrm{I}$ & $\mathrm{I}$ & $\mathrm{I}$ & $\mathrm{I}$ & $\mathrm{I}$ & $\mathrm{I}$ & $\mathrm{I}$ & $\mathrm{I}$ & $\mathrm{I}$ & $\mathrm{I}$ & $\mathrm{I}$ \\
\hline
\end{tabular}

\begin{tabular}{c|cccccccccccccc}
\hline \multicolumn{1}{c|}{ Pontos } & $\mathbf{1 5}$ & $\mathbf{1 6}$ & $\mathbf{1 7}$ & $\mathbf{1 8}$ & $\mathbf{1 9}$ & $\mathbf{2 0}$ & $\mathbf{2 1}$ & $\mathbf{2 2}$ & $\mathbf{2 3}$ & $\mathbf{2 4}$ & $\mathbf{2 5}$ & $\mathbf{2 6}$ & $\mathbf{2 7}$ & $\mathbf{2 8}$ \\
Parâmetro & & & & & & & & & & & & & & \\
\hline $\mathbf{1}$ & 0 & 0 & 0 & 0 & 0 & 0 & 0 & 0 & 0 & 0 & 0 & 0 & 0 & 0 \\
$\mathbf{2}$ & 2 & 2 & 2 & 2 & 2 & 2 & 2 & 2 & 2 & 2 & 2 & 2 & 2 & 2 \\
$\mathbf{4}$ & 2 & 2 & 2 & 2 & 2 & 2 & 2 & 2 & 2 & 2 & 2 & 2 & 2 & 2 \\
$\mathbf{5}$ & 4 & 4 & 4 & 4 & 4 & 4 & 4 & 4 & 4 & 4 & 4 & 4 & 4 & 4 \\
$\mathbf{6}$ & 2 & 2 & 2 & 2 & 2 & 2 & 2 & 2 & 2 & 2 & 2 & 2 & 2 & 2 \\
$\mathbf{7}$ & 0 & 0 & 0 & 0 & 0 & 0 & 0 & 0 & 0 & 0 & 0 & 0 & 0 & 0 \\
$\mathbf{8}$ & 0 & 0 & 0 & 0 & 0 & 0 & 0 & 0 & 0 & 0 & 0 & 0 & 0 & 0 \\
$\mathbf{9}$ & 0 & 0 & 0 & 0 & 0 & 0 & 0 & 0 & 0 & 0 & 0 & 0 & 0 & 0 \\
$\mathbf{1 0}$ & 0 & 0 & 0 & 0 & 0 & 0 & 0 & 0 & 0 & 0 & 0 & 0 & 0 & 0 \\
$\mathbf{1 1}$ & 0 & 0 & 0 & 0 & 0 & 0 & 0 & 0 & 0 & 0 & 0 & 0 & 0 & 0 \\
$\mathbf{1 2}$ & 2 & 2 & 2 & 2 & 2 & 2 & 2 & 2 & 2 & 2 & 2 & 2 & 2 & 2 \\
$\mathbf{1 3}$ & 0 & 0 & 0 & 0 & 0 & 0 & 0 & 0 & 0 & 0 & 0 & 0 & 0 & 0 \\
$\mathbf{1 4}$ & 0 & 0 & 0 & 0 & 0 & 0 & 0 & 0 & 0 & 0 & 0 & 0 & 0 & 0 \\
\hline Pontuação Final & 0 & 0 & 0 & 0 & 0 & 0 & 0 & 0 & 0 & 0 & 0 & 0 & 0 & 0 \\
\hline Situação & 12 & 12 & 12 & 12 & 12 & 12 & 12 & 12 & 12 & 12 & 12 & 12 & 12 & 12 \\
\hline
\end{tabular}

Legenda: 0 a 24 pontos $=\operatorname{Impactado}(\mathrm{I}) / 25$ a 36 pontos $=$ Alterado $(\mathrm{A}) />36$ pontos $=$ Naturais $(\mathrm{N})$ Fonte: Autores do trabalho. 
Tabela 2: Pontuação final para os pontos analisados através do Protocolo de Avaliação Rápida da Diversidade de Habitats em Trechos de Bacias Hidrográficas, em dia seco.

Pontuação Final: Pontos analisados em dia seco

\begin{tabular}{c|cccccccccccccccc}
\hline Pontos & $\mathbf{2 9}$ & $\mathbf{3 0}$ & $\mathbf{3 1}$ & $\mathbf{3 2}$ & $\mathbf{3 3}$ & $\mathbf{3 4}$ & $\mathbf{3 5}$ & $\mathbf{3 6}$ & $\mathbf{3 7}$ & $\mathbf{3 8}$ & $\mathbf{3 9}$ & $\mathbf{4 0}$ & $\mathbf{4 1}$ & $\mathbf{4 2}$ & $\mathbf{4 3}$ & $\mathbf{4 4}$ \\
Parâmetro & & & & & & & & & & & & & & & & \\
\hline $\mathbf{1}$ & 0 & 0 & 0 & 0 & 0 & 0 & 0 & 0 & 0 & 0 & 0 & 0 & 0 & 0 & 0 & 0 \\
$\mathbf{2}$ & 2 & 2 & 2 & 2 & 2 & 2 & 2 & 2 & 2 & 2 & 2 & 2 & 2 & 2 & 2 & 2 \\
$\mathbf{3}$ & 2 & 2 & 2 & 2 & 2 & 2 & 2 & 2 & 2 & 2 & 2 & 2 & 2 & 2 & 2 & 2 \\
$\mathbf{4}$ & 2 & 2 & 2 & 2 & 2 & 2 & 2 & 2 & 2 & 2 & 2 & 2 & 2 & 2 & 2 & 2 \\
$\mathbf{5}$ & 4 & 4 & 4 & 4 & 4 & 4 & 4 & 4 & 4 & 4 & 4 & 4 & 4 & 4 & 4 & 4 \\
$\mathbf{6}$ & 0 & 0 & 0 & 0 & 0 & 0 & 0 & 0 & 0 & 0 & 0 & 0 & 0 & 0 & 0 & 0 \\
$\mathbf{7}$ & 0 & 0 & 0 & 0 & 0 & 0 & 0 & 0 & 0 & 0 & 0 & 0 & 0 & 0 & 0 & 0 \\
$\mathbf{8}$ & 0 & 0 & 0 & 0 & 0 & 0 & 0 & 0 & 0 & 0 & 0 & 0 & 0 & 0 & 0 & 0 \\
$\mathbf{9}$ & 0 & 0 & 0 & 0 & 0 & 0 & 0 & 0 & 0 & 0 & 0 & 0 & 0 & 0 & 0 & 0 \\
$\mathbf{1 0}$ & 0 & 0 & 0 & 0 & 0 & 0 & 0 & 0 & 0 & 0 & 0 & 0 & 0 & 0 & 0 & 0 \\
$\mathbf{1 1}$ & 0 & 0 & 0 & 0 & 0 & 0 & 0 & 0 & 0 & 0 & 0 & 0 & 0 & 0 & 0 & 0 \\
$\mathbf{1 2}$ & 0 & 0 & 0 & 0 & 0 & 0 & 0 & 0 & 0 & 0 & 0 & 0 & 0 & 0 & 0 & 0 \\
$\mathbf{1 3}$ & 0 & 0 & 0 & 0 & 0 & 0 & 0 & 0 & 0 & 0 & 0 & 0 & 0 & 0 & 0 & 0 \\
$\mathbf{1 4}$ & 0 & 0 & 0 & 0 & 0 & 0 & 0 & 0 & 0 & 0 & 0 & 0 & 0 & 0 & 0 & 0 \\
\hline Pontuação & \multirow{2}{*}{10} & 10 & 10 & 10 & 10 & 10 & 10 & 10 & 10 & 10 & 10 & 10 & 10 & 10 & 10 & 10 \\
Final & & & & & & & & \\
Situação & I & I & I & I & I & I & I & I & I & I & I & I & I & I & I & I \\
\hline
\end{tabular}

\begin{tabular}{|c|c|c|c|c|c|c|c|c|c|c|c|c|c|c|c|c|}
\hline $\begin{array}{l}\text { Pontos } \\
\text { Parâmetro }\end{array}$ & 45 & 46 & 47 & 48 & 49 & 50 & 51 & 52 & 53 & 54 & 55 & 56 & 57 & 58 & 59 & 60 \\
\hline 1 & 0 & 0 & 0 & 0 & 0 & 0 & 0 & 0 & 0 & 0 & 0 & 0 & 0 & 0 & 0 & 0 \\
\hline 2 & 2 & 2 & 2 & 2 & 2 & 2 & 2 & 2 & 2 & 2 & 2 & 2 & 2 & 0 & 2 & 2 \\
\hline 3 & 2 & 2 & 2 & 2 & 2 & 2 & 2 & 2 & 2 & 2 & 2 & 2 & 2 & 2 & 2 & 2 \\
\hline 4 & 2 & 2 & 2 & 2 & 2 & 2 & 2 & 2 & 2 & 2 & 2 & 2 & 2 & 2 & 2 & 2 \\
\hline 5 & 4 & 4 & 4 & 4 & 4 & 4 & 4 & 4 & 4 & 4 & 4 & 4 & 4 & 4 & 4 & 4 \\
\hline 6 & 0 & 0 & 0 & 0 & 0 & 0 & 0 & 0 & 0 & 0 & 0 & 0 & 0 & 0 & 0 & 0 \\
\hline 7 & 0 & 0 & 0 & 0 & 0 & 0 & 0 & 0 & 0 & 0 & 0 & 0 & 0 & 0 & 0 & 0 \\
\hline 8 & 0 & 0 & 0 & 0 & 0 & 0 & 0 & 0 & 0 & 0 & 0 & 0 & 0 & 0 & 0 & 0 \\
\hline 9 & 0 & 0 & 0 & 0 & 0 & 0 & 0 & 0 & 0 & 0 & 0 & 0 & 0 & 0 & 0 & 0 \\
\hline 10 & 0 & 0 & 0 & 0 & 0 & 0 & 0 & 0 & 0 & 0 & 0 & 0 & 0 & 0 & 0 & 0 \\
\hline 11 & 0 & 0 & 0 & 0 & 0 & 0 & 0 & 0 & 0 & 0 & 0 & 0 & 0 & 0 & 0 & 0 \\
\hline 12 & 0 & 0 & 0 & 0 & 0 & 0 & 0 & 0 & 0 & 0 & 0 & 0 & 0 & 0 & 0 & 0 \\
\hline 13 & 0 & 0 & 0 & 0 & 0 & 0 & 0 & 0 & 0 & 0 & 0 & 0 & 0 & 0 & 0 & 0 \\
\hline 14 & 0 & 0 & 0 & 0 & 0 & 0 & 0 & 0 & 0 & 0 & 0 & 0 & 0 & 0 & 0 & 0 \\
\hline $\begin{array}{c}\text { Pontuação } \\
\text { Final }\end{array}$ & 10 & 10 & 10 & 10 & 10 & 10 & 10 & 10 & 10 & 10 & 10 & 10 & 10 & 8 & 10 & 10 \\
\hline Situação & I & I & I & I & I & I & I & I & I & I & I & I & I & I & I & I \\
\hline
\end{tabular}

Legenda: 0 a 24 pontos $=$ Impactado (I) $/ 25$ a 36 pontos $=$ Alterado $(A) />36$ pontos $=$ Naturais (N)

Fonte: Autores do trabalho.

O córrego da Estiva foi dividido em cinco trechos, cada um contendo 12 pontos, foi aplicado o teste estatístico Kruskal-Wallis para se avaliar as diferenças entre as medianas para os cinco trechos. Também foi analisada, com os testes estatísticos, a diferença entre as margens 
(esquerda e direita) e a condição do tempo (chuvoso e seco).

A aplicação do teste utiliza os valores numéricos transformados em postos e agrupados num só conjunto de dados. A comparação dos grupos é realizada por meio da mediana dos postos (COSTA et al., 2014). Para o teste de Kruskal-Wallis, foram feitos os três testes não paramétricos avaliando os trechos, margens e condição do tempo.

De acordo com o resultado do teste Kruskal-Wallis para a comparação das médias entre os cinco trechos, não houve diferença significativa entre eles e o nível de confiabilidade do teste foi de mais de 95\%, conforme Tabela 3.

Nestas mesmas condições estatísticas, foram avaliadas comparativamente, as margens direta e esquerda do córrego da Estiva (Betim/MG) e não foram encontradas diferenças significativas entre elas (Tabela 4). Apesar da diferença entre as medianas, o teste apresentou confiabilidade, indicando assim, que o mesmo encontrou semelhanças entre os dados. Logo, tanto a margem direita quanto a margem esquerda, apresentam-se impactadas em consonância com as observações in loco e o Protocolo de Callisto.

Para a comparação entre os dias chuvoso e seco, o teste Kruskal-Wallis revelou que houve diferença estatística significativa, o mesmo apresentou $0 \%$ de confiabilidade indicando assim que não há semelhança entre os dados. Pode-se dizer que, o córrego da Estiva possui uma qualidade ambiental melhor em dia chuvoso em comparação com dia seco. Esta diferença se deve ao fato dos parâmetros odor do córrego e características do fluxo da água, receberem melhores pontuações devido à condição chuvosa do tempo (Tabela 5).

Tabela 3: Comparação da mediana entre os cinco trechos do córrego da Estiva.

\begin{tabular}{ccccc}
\multicolumn{5}{c}{ Média versus Trecho (Kruskal-Wallis) } \\
\hline Trecho & $\mathbf{N}$ & Median & Ave Rank & $\mathbf{Z}$ \\
\hline 1 & 12 & 0,7143 & 28 & $-0,56$ \\
2 & 12 & 0,7857 & 31,8 & 0,28 \\
3 & 12 & 0,7857 & 31,8 & 0,28 \\
4 & 12 & 0,7857 & 31,8 & 0,28 \\
5 & 12 & 0,7143 & 29,3 & $-0,27$ \\
Overall & 60 & & 30,5 & \\
& $\mathrm{H}=0,50$ & $\mathrm{DF}=4$ & $\mathrm{P}=0,974$ & \\
& $\mathrm{H}=0,65$ & $\mathrm{DF}=4$ & $\mathrm{P}=0,957$ &
\end{tabular}

Fonte: Autores do trabalho.

Tabela 4: Comparação entre as margens direita e esquerda do córrego da Estiva.

\begin{tabular}{ccccc}
\multicolumn{5}{c}{ Margem Direita Versus Margem Esquerda (Kruskal-Wallis) } \\
\hline Margem & $\mathbf{N}$ & Median & Ave Rank & $\mathbf{Z}$ \\
\hline Direita & 36 & 0,7143 & 28 & $-1,34$ \\
Esquerda & 24 & 0,8571 & 34,2 & 1,34 \\
Overall & 60 & & 30,5 & \\
\hline & $\mathrm{H}=1,80$ & $\mathrm{DF}=1$ & $\mathrm{P}=0,179$ \\
& $\mathrm{H}=2,37$ & $\mathrm{DF}=1$ & $\mathrm{P}=0,124$ \\
\hline
\end{tabular}

Fonte: Autores do trabalho. 
Tabela 5: Comparação dos pontos marcados no córrego da Estiva em dia chuvoso e seco.

\begin{tabular}{ccccc}
\multicolumn{5}{c}{ Dia Seco Versus Dia Chuvoso (Kruskal-Wallis) } \\
\hline Dia & $\mathbf{N}$ & Median & Ave Rank & Z \\
\hline Chuvoso & 28 & 0,8571 & 46,5 & 6,64 \\
Seco & 32 & 0,7143 & 16,5 & $-6,64$ \\
Overall & 60 & & 30,5 & \\
\hline & $\mathrm{H}=44,07$ & $\mathrm{DF}=1$ & $\mathrm{P}=0,000$ \\
& $\mathrm{H}=57,93$ & $\mathrm{DF}=1$ & $\mathrm{P}=0,000$ \\
\cline { 3 - 4 }
\end{tabular}

Fonte: Autores do trabalho

Somente após as etapas de avaliação dos principais impactos, seu potencial impactante e da qualidade ambiental do córrego é possível propor medidas mitigadoras, ou seja, ações que permitem um maior controle em relação aos impactos causados pela ação antrópica. Para os principais impactos observados no córrego da Estiva, foram propostas algumas medidas mitigadoras que buscam amenizar, ou até mesmo, sanar os problemas observados. São elas:

- Ausência de mata ciliar e erosão ao longo das margens: adequação das estruturas de drenagem e recuperação das margens ao longo do córrego com vegetação nativa (VANDERLEY \& SILVA, 2015), contribuindo para a infiltração de águas pluviais e preservação dessas margens (SILVEIRA et al., 2013). Conservação da natureza: o manejo adequado dos recursos naturais compreendendo a preservação, manutenção, utilização sustentável, restauração e/ou recuperação do ambiente natural, para que possa assegurar às atuais gerações os recursos naturais necessários para a sua sobrevivência, mantendo seu potencial de satisfazer as necessidades e aspirações das gerações futuras, e garantindo a sobrevivência dos seres vivos em geral (BRASIL, 2000).

- Presença de animais vetores de doenças: combate aos animais vetores de doenças através do tratamento de esgotos antes de seu descarte in natura, proporcionando água de melhor qualidade, ou mesmo, potável (SANTOS et al., 2013; BRITO et al., 2014).

- Moradia irregular: remoção das ocupações irregulares; fiscalização para o cumprimento de leis de ocupação do solo (SILVEIRA et al., 2013). As zonas de uso e ocupação do solo da Área Central de Betim compreendem espaços, estabelecimentos e instalações sujeitos à preservação, tais como: áreas de preservação paisagística ou de proteção de mananciais, bosques, matas naturais, reservas florestais e minerais, parques urbanos, monumentos históricos e áreas de valor estratégico para a segurança pública conforme prevê a Lei no 5177 de 10 de Agosto de 2011, que dispõe sobre o do Plano Diretor do município de Betim. É evidente a necessidade de mais estudos de planejamento urbano para a região (ALVES et al., 2013).

- Disposição inadequada dos resíduos sólidos: A Constituição brasileira definiu em 1988 que a gestão de resíduos sólidos é uma responsabilidade do governo local. A Política Nacional de Resíduos Sólidos estabelece que todos os grandes produtores (municípios e empresas de grande e médio porte) elaborem e implementem seus Planos de Gerenciamento de Resíduos Sólidos (BARROS, 2012). É preciso que seja cobrado da Secretaria Municipal de Infraestrutura e do departamento responsável pelo gerenciamento e coleta de resíduos sólidos do município, um monitoramento e fiscalização, para que não mais ocorra disposição inadequada de resíduos sólidos (CRISPIM et al., 2013). A Política Nacional de Resíduos Sólidos (PNRS) prevê a prevenção e a redução na geração de resíduos, tendo como proposta a prática de hábitos de consumo sustentável e um conjunto de instrumentos para propiciar o aumento da reciclagem e da reutilização dos resíduos sólidos; aquilo que tem valor econômico e pode ser reciclado ou reaproveitado; e a destinação ambientalmente adequada dos rejeitos, aquilo que não pode ser reciclado ou reutilizado (BRASIL, 2010). Conforme os resultados do estudo demonstraram, o córrego da Estiva sofre principalmente com a disposição inadequada de resíduos sólidos domiciliares e de construção civil, uma das medidas cabíveis, conforme 
Marquezini et al. (2014), seria a capacitação de moradores locais como coletores de material reciclável, a fim de diminuir a elevada quantidade de material descartado em suas margens, trazendo também uma fonte extra de renda para os mesmos. A implantação de mais pontos de coleta por parte do sistema de limpeza urbana, visto que no entorno do córrego quase não há, assim como a fiscalização com o intuito de prevenir o descarte de resíduos sólidos de construção civil, muitas vezes praticados por moradores de outras regiões do município de Betim.

- Lançamento de efluentes líquido: realizar levantamento completo de ligações clandestinas de esgoto na rede de águas pluviais e adequar o sistema de esgotamento sanitário e drenagem urbana do município (GOMES et al., 2014). A Política Nacional de Recursos Hídricos assegura a articulação do planejamento de recursos hídricos com as necessidades e exigências dos seus usuários e com os planejamentos regional, estadual e nacional (BRASIL, 1997). As tecnologias alternativas surgem com o intuito de solucionar problemas ambientais, como os que envolvem a contaminação dos recursos hídricos e do solo devido ao lançamento indiscriminado de esgoto, assim fazem-se uso de plantas que auxiliam no tratamento dos mesmos (SILVEIRA \& NARIELE, 2014).

- Queimadas de resíduos sólidos e para limpeza de lotes: Coleta regular dos resíduos sólidos e realização de capina no entorno das margens pela prefeitura. Além da organização por parte de órgãos competentes de palestras para jovens e adultos sobre a importância do manejo ecológico do solo (VANDERLEY \& SILVA, 2015).

- Neste contexto, observa-se que há necessidade de um processo educativo envolvendo a comunidade da AID e da AII do córrego do Estiva, propondo informações que esclareçam sobre a necessidade de preservação do curso d'agua e dos seus recursos naturais e que essas ações poderão melhorar não só a qualidade ambiental, mas também aquelas relacionadas à saúde e, consequentemente, na melhoria da qualidade de vida dessa comunidade. Por esse motivo, a educação socioambiental, torna-se relevante na conservação do ambiente e na qualidade de vida das comunidades conforme Silva et al. (2012).

É possível perceber que, diante dos problemas e impactos apresentados, algumas medidas mitigadoras e de prevenção, como as listadas anteriormente, precisam ser colocadas em prática para a prevenção dos problemas gerados pela ocupação irregular das margens do córrego da Estiva, é necessário também a implantação de um planejamento urbano adequado, que atenda às necessidades da demanda populacional, levando em consideração a preservação do córrego.

\section{Considerações Finais}

Considera-se que o presente trabalho alcançou os objetivos propostos. Os principais impactos foram identificados e a avaliação da qualidade ambiental do córrego da Estiva, no município de Betim (MG) mostrou que os 60 pontos analisados apresentam graves fatores de degradação, situação semelhante foi constatada pelos testes estatísticos em que todos os trechos foram considerados impactados. Os problemas encontrados no córrego interferem tanto na qualidade de vida dos habitantes desta região do município como em sua dinâmica ambiental. A partir da avaliação e do conhecimento da situação do córrego da Estiva, foi possível sugerir medidas mitigadoras que possam atenuar a, curto prazo, os problemas visualizados e melhorar a qualidade de vida na região. Para a melhoria da qualidade socioambiental da área estudada e diante das situações abordadas, faz-se necessário ampliar estudos na região, como forma de sensibilizar os órgãos competentes e a sociedade em geral para uma reflexão sobre a questão ambiental. Ressalta-se a viabilidade do Protocolo de Callisto para análise rápida de impactos ambientais em um curso d'água.

\section{Referências}

ALVES, R. E et al (2013) Análise dos impactos ambientais do uso do solo urbano em áreas declivosas na cidade de Jataí (GO). Boletim Campineiro de Geografia, v. 3, n. 2, 2013.
ARAÚJO, E. S; BARBOSA, M. P (2010) Diagnóstico preliminar de impactos 
ambientais no trecho urbano do córrego São João em Porto Nacional, estado do Tocantins. Brasil: Revista Eletrônica do Curso de Geografia - UFG, Jataí-GO, n.14, jan-jun.

BAILLY, D et al (2012) Diagnóstico ambiental e impactos sobre a vegetação ciliar da microbacia do córrego da ponte, área de proteção ambiental do rio Iguatemi. Revista em Agronegócios e Meio Ambiente, v.5, n.2, p. 409-427, maio/ago.

BARBAROTO, J. J. L; SILVA, D. F; LEAL, A. C (2013) Caracterização ambiental da bacia do córrego do Cedrinho no município de Presidente Prudente e propostas para recuperação da área. São Paulo: Tópos, v.7, nn 1, p. 58-84.

BARROS, R.T.V (2012) O Papel da Universidade na Gestão de Resíduos Sólidos:o Caso da Universidade Federal de Minas Gerais UFMG. 5o Seminário Internacional de Planejamento e Gestão Ambiental URBENVIRON Brasília.

BELLUTA, I. et al (2014) Assoreamento de lago na sub-bacia do córrego da Cascata, em Botucatu (SP): implicações morfométricas. Caminhos de Geografia Uberlândia v. 15, n. 50 Jun/2014 p. 172-186.

BETIM. Lei no 5177 de 10 de Agosto de 2011. Altera a lei $\mathrm{n}^{\mathrm{o}}$ 4574, de 02 de Outubro de 2007, que dispõe sobre a revisão do Plano Diretor do município de Betim. Betim, 2011

BETIM. Prefeitura municipal de Betim: portal Betim. 2014. Disponível em < http://www.betim.mg.gov.br/home/41498\%3B 61829\%3B03\%3B0\%3B0.asp > Acessado em Abril de 2014

BITTENCOURT, C. R et al (2012) Levantamento dos impactos ambientais antrópicos na APA do Itapiracó em São Luís do Maranhão. VII Connepi: Congresso Norte Nordeste de Pesquisa e Inovação, 19-21 de outubro.

BRASIL, Conselho Nacional do Meio Ambiente. (1986) Resolução Conama no 001/86. Art. $1^{\text {o }}$. Dispõe sobre critérios básicos e diretrizes gerais para a avaliação de impacto ambiental. Data da legislação: 23/01/1986 - Publicação DOU, de 17/02/1986, págs. 2548-2549. Disponível em < http://www.mma.gov.br/port/conama/legiabr e.cfm?codlegi=23> Acessado em Maio de 2014.

BRASIL, Política nacional do meio ambiente (1981) Lei № 6.938, de 31 de Agosto de 1981. Dispõe sobre a Política Nacional do Meio Ambiente, seus fins e mecanismos de formulação e aplicação, e dá outras providências. Disponível em<http://www.planalto.gov.br/ccivil_03/Leis /L6938.htm > Acessado em Setembro de 2015

BRASIL, Política Nacional Recursos Hídricos (1997) Lei № 9433, de 8 de Janeiro de 1997. Institui a Política Nacional de Recursos Hídricos, cria o Sistema Nacional de Gerenciamento de Recursos Hídricos, regulamenta o inciso XIX do art. 21 da Constituição Federal, e altera o art. $1^{\mathrm{o}}$ da Lei $\mathrm{n}^{\mathrm{o}}$ 8.001, de 13 de março de 1990, que modificou a Lei $\mathrm{n}^{\mathbf{0}} 7.990$, de 28 de dezembro de 1989 . Disponível em <http://www.planalto.gov.br/ccivil_03/leis/194 33.htm> Acessado em Novembro de 2014.

BRASIL, Sistema Nacional de Unidades de Conservação da Natureza (2000) Lei № 9.985, de 18 de Julho de 2000. Institui o Sistema Nacional de Unidades de Conservação da Natureza - SNUC, estabelece critérios e normas para a criação, implantação e gestão das unidades de conservação. Disponível em $<$

http://www.planalto.gov.br/ccivil_03/leis/1998 5.htm> Acessado em Novembro de 2014.

BRASIL, Política Nacional de Resíduos Sólidos (2010) Lei № 12.305, de 2 de Agosto de 2010 . Institui a Política Nacional de Resíduos Sólidos; altera a Lei no 9.605, de 12 de fevereiro de 1998; e dá outras providências. Disponível em $<$ http://www.planalto.gov.br/ccivil_03/_ato20 07-2010/2010/lei/112305.htm> Acessado em Novembro de 2014. 
BRITO, A. M et al (2014) Efeitos da ocupação desordenada às margens do córrego Neblina em Araguaína (TO). Revista Tocantinense de Geografia, Araguaína (TO), Ano 03, n o 01 , p. 11- 21, jan - jul

CALLISTO, M.; FERREIR, W. F.; MORENO, P.; GOULART, P.; PETRUCCIO, M (2002) Aplicação de um protocolo de avaliação rápida da diversidade de habitats em atividades de ensino em pesquisa (MG-RJ). Acta Limnol. Bras., 14(1) p. 91-98.

CEPEMAR (2004) Áreas de influência da atividade. In: EIA - Estudo de impacto ambiental do campo de Jubarte. Brasil: Rev. 00, março.

CHERUBINI, R (2008) Avaliação ambiental do sistema de coleta e disposição final de resíduos sólidos urbanos do município de Farroupilha-RS. Caixias do Sul:[s.n.].

COSTA, T. C. C; SOUZA, M.G; BRITES, R.S (1996) Delimitação e caracterização de áreas de preservação permanente, por meio de um sistema de informações geográficas (SIG). BAHIA: Anais VIII Simpósio Brasileiro de Sensoriamento Remoto, Salvador, Brasil, 1419, abril, INPE, p. 121-127

COSTA, H. M. D; ANDRADE, M. C. D; LESSA, M. D; RAMOS, V. D (2014) Cinética de cristalização não-isotérmica de resíduos de polietileno de alta densidade (PEAD). Polímeros, São Carlos, vol.24, n.4, pp. 521528. Julho/Agosto.

CRISPIM, D. L; LEITE, R. P; CHAVES A. D. C. G; FERREIRA, A. C; MARACAJÁ, P. B (2013) Impactos ambientais no açude do bairro nova vida em Pombal - PB. Revista Brasileira de Gestão Ambiental GVAA - Grupo Verde de Agroecologia e Abelhas- Pombal-PB-Brasil, V . 7, n. 1, p. 102 - 129 , jan - mar.

DIAS, S. M. C (2013) Planos e programas: avaliação do impacte no ambiente e território. Dissertação: (Mestre em Engenharia do Ambiente, perfil Gestão e Sistemas Ambientais) - Universidade Nova de Lisboa.
FRANÇA, L. O; RODRIGUES, A. S. L; MALAFAIA, G (2013) Diagnóstico ambiental do córrego do Açude, Orizona-GO por meio de um protocolo de avaliação rápida de rios. Revista Tropica: Ciências Agrárias e Biológicas, v.7, n.1

FERREIRA, E. M et al (2014) Disposição final dos resíduos sólidos urbanos: diagnóstico da gestão do município de Santo Antônio de Goiás. Revista Monografias Ambientais REMOA v.14, n.3, mai-ago. 2014, p.3401-3411

GARCIA. S. M. N. P (2010) Os planos diretores e o planejamento urbano no aglomerado Cuiabá/Várzea Grande - MT. 2010. Dissertação (Mestrado em Arquitetura e Urbanismo) - Faculdade de Arquitetura e Urbanismo, Universidade de São Paulo. São Paulo, 2010. Disponível em: http://www.teses.usp.br

GOMES, P. A. J. S; LIMA, S. D; GOLIN, R; FIGUEIREDO, D. M; LIMA, Z. M; MORAIS E. B; DORES, E. F. G. C (2014) Qualidade de uma Microbacia com Fins de Abastecimento Público, Chapada dos Guimarães, MT. HOLOS, Ano 30, Vol. 4.

GOUVEIA, N (2012) Resíduos sólidos urbanos: impactos socioambientais e perspectiva de manejo sustentável com inclusão social. São Paulo: Ciência \& Saúde Coletiva, 17 (6): 15031510.

LOPES, F. W. A.; CARVALHO, A.; MAGALHÃES JR, A.P (2011) Levantamento e avaliação dos impactos ambientais em áreas de uso recreacional das águas na bacia do Alto Rio das Velhas. Rio de Janeiro: Caderno Virtual de Turismo, v. 11, n. 2, p.177-190 ago

MARINHO, M. M. O; FILHO, S. S. A; ORRICO, S. R. M; SANTOS, F. C (2012) Avaliação de impacto ambiental como instrumento de estímulo à produção limpa: desafios e oportunidades no estado da Bahia. São Paulo: Revista de Gestão Social e Ambiental, v.6, n.3, p.132-144, set./dez.

MARQUEZINE, L. C et al (2014) Aplicação da Avaliação Ambiental Simplificada (ASS) em 
função do uso da terra em bacia hidrográfica urbana. Bol. geogr., Maringá, v. 32, n. 3, p. 138-150, set.-dez

MUCELIN, C. A; BELLINI, M (2008) Lixo e impactos ambientais perceptíveis no ecossistema urbano. Brasil: Sociedade \& Natureza, Uberlândia, 20 (1): 111-124, jun.

PAZ, F. N. V; PAIVA, J. A (2011) Levantamento dos possíveis impactos ambientais pela ação antrópica nos córregos Jenipapo e Cará no município de Aragominas - TO. Brasil: Educação, Gestão e Sociedade: revista da Faculdade Eça de Queiros, ISNN 2179-9636, Ano 1, numero 4, dezembro.

ROCHA, G. L (2012) Avaliação da aplicação do estudo de impacto ambiental em projeto de loteamento urbano localizado em área de proteção de mananciais: utp de Pinhais, utp do Itaqui e apa de Piraquara - região metropolitana de Curitiba/PR. Dissertação: (Pós-Graduação em Engenharia da Construção Civil, Áreas de Concentração em Ambiente Construído e Gestão) Universidade Federal do Paraná.

SANTOS, et al. (2013) A qualidade da água para o consumo humano: uma discussão necessária. Revista Brasileira de Gestão Ambiental GVAA - Grupo Verde de Agroecologia e Abelhas- Pombal-PB, V. 7, n. 2, p. 19-26, abr - jun.

SILVA, D. N; MORAIS, R. F; VIERIA, Z. S. S (2012) Avaliação dos impactos ambientais do córrego Barbado no município de Cuiabá, Mato Grosso. Brasil: Anais 4⿳⺈ Simpósio de Geotecnologias no Pantanal, Bonito, MS, 2024 de outubro, Embrapa Informática Agropecuária/INPE, p. 162 -170

SILVA, J. C. R (2012) Impactos ambientais sobre a rede de drenagem: o traçado da rua Fortaleza, bairro Santa Cruz, Campina Grande, PB. Monografia: (Licenciatura Plena em Geografia) - Universidade Estadual da Paraíba.

SILVA, L. C; LATINI, R. O (2014) Problemas presentes em estudos de impactos ambientais
(EIA) de empreendimentos poluidores e algumas de suas possíveis consequências. Belo Horizonte: Centro Universitário Metodista Izabela Hendrix.

SILVA, L. S; SILVE, E (2015) Impactos socioambientais causados pelo lixo na cidade de Itaguatins. Revista Tocantinense de Geografia, Araguaína (TO), Ano 04, n.0 01, jan-jul.

SILVA, R. A et al (2012) Impactos Ambientais Causados pela expansão urbana do bairro Inconfidentes, Viçosa, MG. Revista Científica Univiçosa - Volume 3 - n. 1 - Viçosa-MG - jan. - dez

SILVEIRA, A; GUARIENTI, R.M; LIMA, E.B.N.R (2013) Análise dos aspectos fisiográficos, socioeconômicos, de saneameto e de uso e ocupação do solo utilização uma bacia hidrográfica urbana como unidade territorial: estudo de caso da bacia do Córrego Barbado (CUIABÁ-MT). Revista de Engenharia e Tecnologia V. 5, No. 2, Agosto.

SILVEIRA, D. F, NARIELE, R.A (2014) Avaliação da eficiência do tratamento de esgoto por estação de zonas de raízes. Universidade Federal do Paraná. Francisco Beltrão.

VANDERLEY, L. D. M; SILVA, M. C (2015) Degradação ambiental no córrego Mato Verde em Babaçulândia - TO. Revista GeoAmazônia Belém, v. 03, n. 05, p. 52 - 62, jan./jun.

VIEIRA, L. R et al (2015) A questão do saneamento no espaço rural: uma abordagem ambiental em três localidades rurais do município de Nova Palma, RS. Revista Eletrônica em Gestão, Educação e Tecnologia Ambiental Santa Maria, v. 19, n. 1, jan.-ab, p. 38-50 